\title{
Design and Construction of the Cylindrical Slit Type Shore Structures
}

\author{
Joong Woo Leeł, Ki-Dae Nam*, Sang-Gill Park**, Sug-Moon Kim***, Seok-Jin Kang**** \\ † Division of Civil and Environmental Engineering, Korea Maritime University, Busan 606-791, Republic. of Korea \\ *,**,**** Dept. of Civil and Environmental Engineering, Korea Maritime University, Busan 606-791, Republic. of Korea \\ *** Chief Executive Officer of Buman Construction
}

\begin{abstract}
In this study, a series of laboratory experiments were carried out to investigate the weak reflection of regular and random water waves over a train of protruded permeable shore structures. A cylindrical slit type breakwater and the alternatives are employed and compared for reflecting and transmitting capabilities of incident waves including wave forces. A series of random waves were generated by using the Bretschneider-Mitsuyasu frequency and directional spectrum. Measured spectrum of irregular waves without breakwaters is verified by comparing with those of the input waves generated. Weak reflection is occurred at the breakwater center of the peak frequency. If the row of breakwaters is fixed at three layers and the relative height of breakwater is fixed at 0.6, around $45 \%$ of incident wave energy is reflected to offshore. It is also found that the transmission of directional random waves increases as the maximum frequency parameter increases. A very good agreement is observed. Reflection coefficients of permeable submerged breakwaters are less than those of impermeable breakwaters. The upside-down $L$ shape is recommended for a small fishery harbor mooring in terms of reflecting capability and of practical application. The final design was applied to the wharf of a small beach of Seolly, near Namhae at the southeast coast of Korea.
\end{abstract}

Key words : cylindrical slit type breakwater, directional spectrum, permeable, reflection, transmission, wave force

\section{Introduction}

Recently, most of coastal areas are tremendously changed by reclamation and construction of coastal structures such as dikes, revetments, breakwaters, jetties, and groins, etc. These structures cause water circulation problems together with bottom and coastline changes. Extension of harbor scale established newly necessity of prolong the existing breakwaters, and thereby the extended harbor area arrived to the limit of water quality and accretion and erosion problem. Sometimes the sand is eroded from the beaches, requiring repeated artificial nourishment. The local communities claim on these and request the government to control this matter. Blocked breakwater construction enhances the protection from the wave attack to the coast and harbor area but constrains water circulation for those areas. When a constraint water area of small tidal motion brings a sudden destruction of natural flow environment, it becomes worse as it exceeds the limit of the harbor self purification capacity. Also, the strong multiple reflections of waves generate problem in safe mooring of vessel because the wave heights in this area are increased by reflection and most of wave energies enter to the harbor basin. In recent years the research for the construction of coastal structures for seawater exchange has shown various shapes adopting slit type caissons. One example for that in Korea is the wave overtopping well type breakwater which had built in Mukho harbor (KORDI, 2005). The seawater circulation had promoted in the inner harbor and the water quality was improved quite well. Design of seawater exchange breakwater had shown the proper flux through this breakwater caused flow inside the inner harbor, and still it had met for the request of harbor tranquility even for resisting the strong wave force. It was necessary to construct the extra overtopping wave well. In this study, we introduced a series of design for shore structures improving the efficiency of seawater exchange together with tranquility behind breakwater. It is investigated in terms of the structural stability, wave transmission and reflection, and wave force by these designs and introduced the field construction of units and installation of the units to the planned wharf area.

\footnotetext{
† Corresponding author : Joong Woo Lee, jwlee@hhu.ac.kr 051)410-4461

* namkidae@lycos.co.kr 051)140-4981

** sangila06@hanmail.net

*** ksone77@yahoo.co.kr 051)515-8050

****soehowlk@nate.com
} 


\section{Experimental facility}

\subsection{Water tank and wave generator}

The tests were executed in the water tank of Korea Maritime University. The dimensions of the flume are length of $28 \mathrm{~m} \times$ height of $1 \mathrm{~m} \mathrm{x}$ width of $5.4 \mathrm{~m}$ with a maximum water depth of $0.8 \mathrm{~m}$. The capability of wave generator in hydraulic piston form presented Table 1 . A capacitance type wave gauge is attached to the wave generator paddles and used for the control of the reflective waves. Waves propagating towards the paddles are absorbed by the paddle and not re-reflected, thereby not disturbing the measurements. The wave generator is capable of generating both regular and irregular waves of any specified spectral. Wave absorber on back side of wave generator was placed and at the wave absorber on the other tank end ripraps on end part of water tank was installed. A system for wave generator paddles is controlled by motion of oil-hydraulic cylinder, and position of wave generator plate is detected consecutively by the sensing device. An acrylic water flume in the water tank of $4000 \mathrm{~mm} \times 910 \mathrm{~mm} \times 1000 \mathrm{~mm}$ was installed to separate the structure way with non structure way because there could be reflection from the side part of water tank due to wide width.

Table 2 Specification of wave generator

\begin{tabular}{|c|c|}
\hline \multicolumn{2}{|c|}{ Capability of wave generator } \\
\hline $\begin{array}{c}\text { Maximum significant wave } \\
\text { height }\end{array}$ & $\begin{array}{c}0.2 \mathrm{~m} \text { (at the depth of water } \\
0.8 \mathrm{~m})\end{array}$ \\
\hline Reappearance wave length & $0.2 \mathrm{~m} \sim 10 \mathrm{~m}$ \\
\hline Reappearance wave period & $0.5 \mathrm{sec} \sim 2 \mathrm{sec}$ \\
\hline
\end{tabular}

\subsection{Measurement device}

Capacitance type wave gauge used in this hydraulic model experiment has a fast reaction rate and less error. This type is suitable for indoor scale model test and the wave height was measured at 5 locations at the same time during the tests. The wave data that measured in wave gauge is linear and measuring range is $\pm 25 \mathrm{~cm}$. It can measure the water level change very precisely within $0.5 \%$ error. Zero calibration before the experiment was done to confirm that the measured corresponds to the signal voltage. $\mathrm{A} / \mathrm{D}$ converter used in this experiment is a device that converts analog signal acquired from the measurement device to digital signal, and D/A converter does similar to controlling means of wave generator, by converting digital signal to analog signal of wave control unit.

\section{Conceptual block and breakwater design for model experiment}

Scale model test of reduced scale of designed block unit and structures is depending on the size of water tank, actual size of structure, dimension of experiment wave, performance of wave generator, etc. The model tests were carried out with a geometrical scale of $1 / 25$. Similarity for the model was based on the required water depth for wave gauge effectiveness and wave generator capabilities. The scale factor is the ratio between the values of prototype and model respectively. Unit blocks used in the experiment are 1:25 block of actual size. Plane and section views for designed unit blocks are shown in Fig.1. Fig.2 shows the final unit block model made.
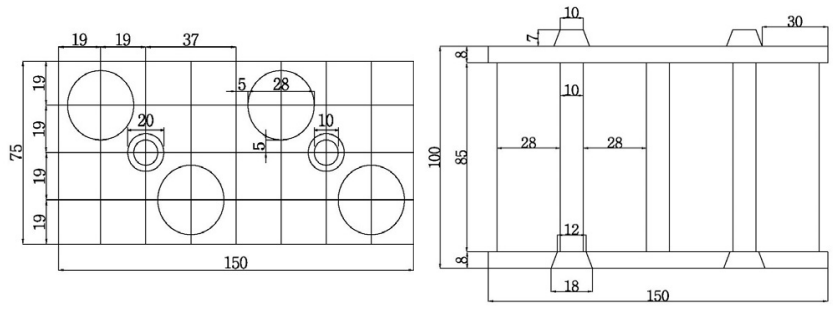

Fig. 1 1:25 Unit block design (a: Plane view, b: Front view)

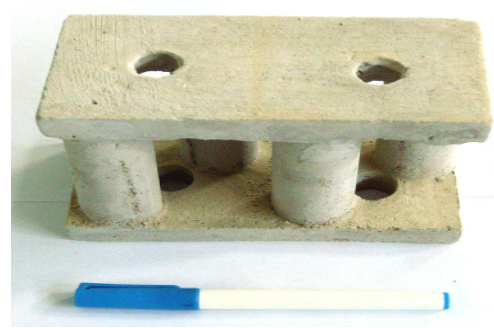

Fig. 2 1:25 Unit block design (Bird's-eye view)

\section{Experimental condition and procedures}

\section{1 Test sections}

To determine the stability of the breakwaters, 3 alternative breakwater test sections above the riprap mound were applied on the breakwaters, considering the environmental condition of Samcheonpo and Namhae water area, southeast coast of Korea, at the water depth of $8 \mathrm{~m}$ and approximately highest higher water level of $9.64 \mathrm{~m}$. The design wave at the structure was $2.5 \mathrm{~m}$ of height and 6 seconds of period. The crest height of the structure was chosen for the dimension limit permitting partial wave overtopping to $\left(1.0 \times H_{1 / 3} \sim\right.$ $\left.1.25 \times H_{1 / 3}\right)$ as in Fig.3. The alternatives of the prototype 
section plan, in reply for solution of the higher transmission which causes the problem of calmness inside harbor, was adopted as in Fig.4. The so harbor top concrete block top plate and an alternative experiment doing by connecting structure go side by side and do comparative analysis each other.

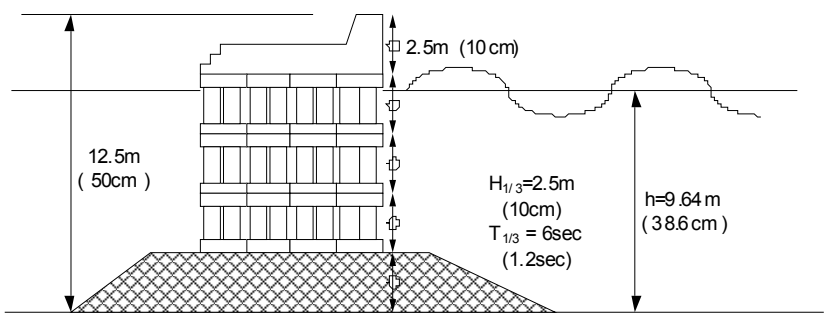

Fig. 2 Prototype of section design
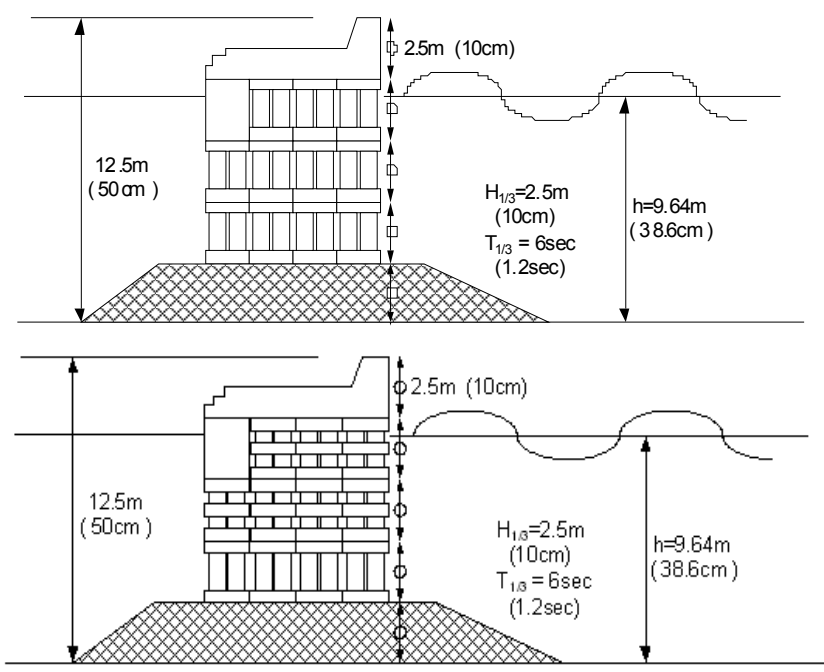

Fig. 3 Alternatives of section design

\subsection{Experimental setup}

The wave heights were measured at 4 locations in Fig. 5(a) to analyze the irregular wave spectrum. Fine adjustment of the wave generator was controlled by the analysis of wave measurement at No.2 and No.3 gauges. Wave generator was adjusted as it possible for target spectrum, and this means that the irregular waves of spectrum was reached at the structure front face correctly. To yield reflection and transmission rates for the structure, 5 wave gauges were set as in Fig. 5(b). For the reflection rate, 3 wave gauges were set at the point of one wave length away and separated the incoming and reflecting waves. Waves from No.4 and No.5 wave gages were analyzed to get the wave transmission rates. Fig.6 is set up for wave forces at the structure face, such as uplift pressure and wave pressure.

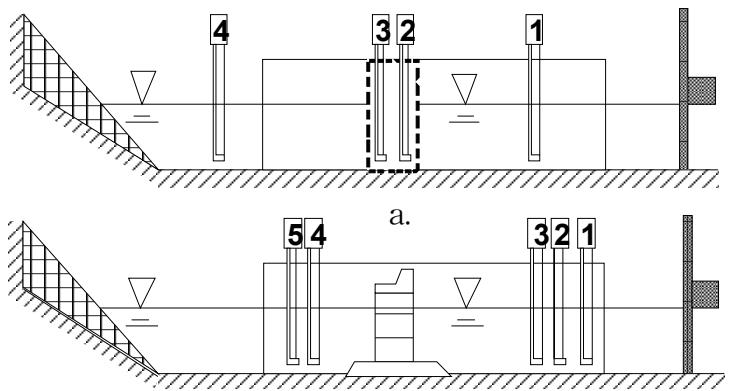

b.

Fig. 4 Experimental setup (a: for irregular wave spectrum, $\mathrm{b}$ : for reflection and transmission rates)

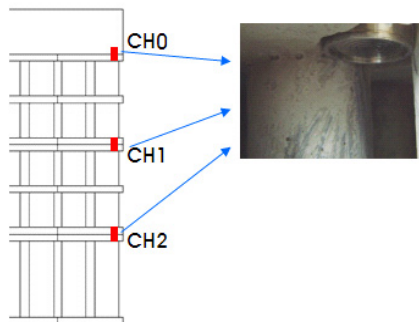

a.

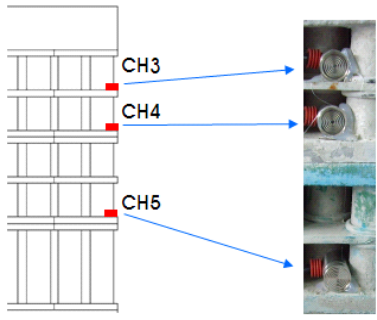

b.
Fig. 5 The locations of wave pressure gauges (a: for uplift pressure, b: for wave pressure)

\subsection{Test procedure and conditions}

Flowchart of irregular wave generation system is appeared at Fig. 7. First, the target wave spectrum is transformed to a spectrum of wave paddle according to characteristic function of paddle operation, the component waves with irregular phase are converted to analogue signals for wave generator after passing through D/A converter. After separation of the incident and reflected waves at the face of structure, the measured incident wave spectrum is being compared to the target spectrum. If both spectra have a good agreement, then we can start the experiment. But in case of big discrepancies, it is necessary to feed back to modification of the characteristic function of paddle operation, repeatedly. For separation of incident wave with respect to reflected wave, we used the method which Goda and Suzuki (1976) had proposed to use wave records from 3 wave gauges with certain interval and adopted the modified Bretschneider-Misuyasu spectrum by Goda (1985) for incident wave as in Eq.(1).

$$
S(f)=0.205 H_{1 / 3}^{2} T_{1 / 3}^{4} f^{b} \exp \left[0.75\left(T_{1 / 3} f\right)^{4}\right]
$$

where, $S(f)$ is the wave energy density function, $f$ is the frequency, and both $H_{1 / 3}$ and $T_{1 / 3}$ are significant wave height and period, respectively. The target spectrum is 
Bretschneider-Mituyasu spectrum, and it was controlled so that the time series of incident wave at the structure face may conform with significant wave height of target wave, and the target spectrum of incident wave was finally derived under non-breaking wave condition. The incident wave conditions at the tide level of HWOST for the local fishery harbor was summarized at Table 2, and Fig.8 shows comparisons of target wave spectrum and incidence wave spectrum. It turned out that they were agreed well each other.

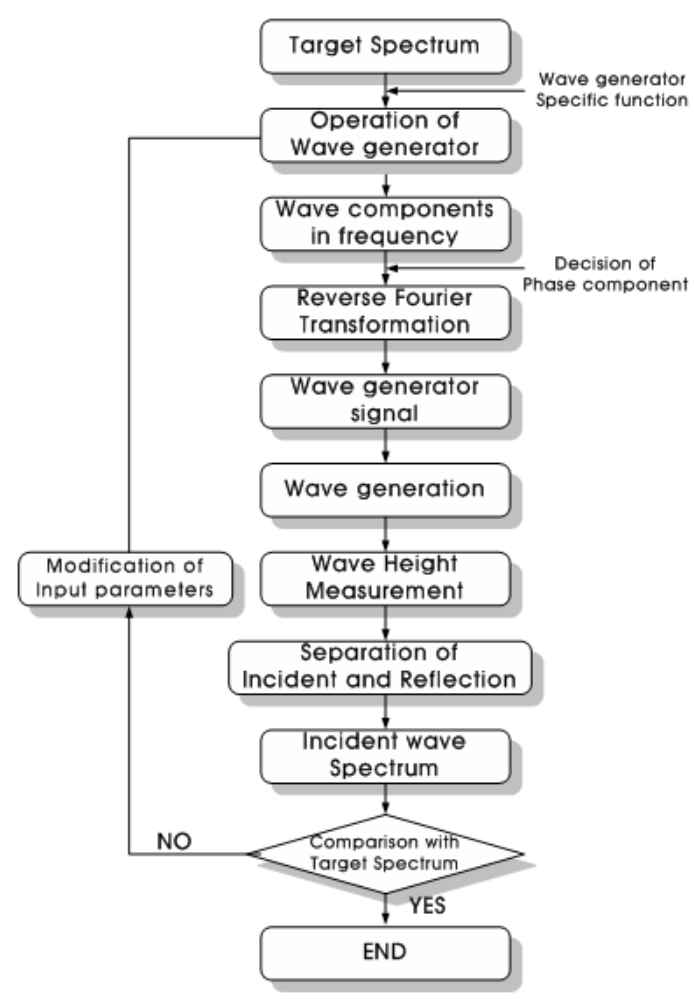

Fig. 6 Flow chart for irregular wave generation

Table 3 Design and model test wave conditions

\begin{tabular}{|c|c|c|c|c|}
\hline \multicolumn{2}{|c|}{$\begin{array}{c}\text { Prototype target } \\
\text { waves }\end{array}$} & \multicolumn{2}{|c|}{ 1/25 Model waves } & \multirow{2}{*}{ Remark } \\
\hline$H_{1 / 3}$ & $T_{1 / 3}$ & $H_{1 / 3}$ & $T_{1 / 3}$ & \\
\hline \multirow{4}{*}{$0.5 \mathrm{~m}$} & $3 \mathrm{~s}$ & $0.02 \mathrm{~m}$ & $0.6 \mathrm{~s}$ & \multirow{12}{*}{$\begin{array}{l}\text { * Impossible to } \\
\text { control the wave } \\
\text { generator, because } \\
\text { it occurs breaking } \\
\text { waves }\end{array}$} \\
\hline & $4 \mathrm{~s}$ & $0.02 \mathrm{~m}$ & $0.8 \mathrm{~s}$ & \\
\hline & $5 \mathrm{~s}$ & $0.02 \mathrm{~m}$ & $1.0 \mathrm{~s}$ & \\
\hline & $6 \mathrm{~s}$ & $0.02 \mathrm{~m}$ & $1.2 \mathrm{~s}$ & \\
\hline \multirow{4}{*}{$1.5 \mathrm{~m}$} & $3 \mathrm{~s}$ & $*$ & $*$ & \\
\hline & $4 \mathrm{~s}$ & $0.06 \mathrm{~m}$ & $0.8 \mathrm{~s}$ & \\
\hline & $5 \mathrm{~s}$ & $0.06 \mathrm{~m}$ & $1.0 \mathrm{~s}$ & \\
\hline & $6 \mathrm{~s}$ & $0.06 \mathrm{~m}$ & $1.2 \mathrm{~s}$ & \\
\hline \multirow{4}{*}{$2.5 \mathrm{~m}$} & $3 \mathrm{~s}$ & $*$ & $*$ & \\
\hline & $4 \mathrm{~s}$ & $*$ & $*$ & \\
\hline & $5 \mathrm{~s}$ & $*$ & $*$ & \\
\hline & $6 s$ & $0.10 \mathrm{~m}$ & $1.2 \mathrm{~s}$ & \\
\hline
\end{tabular}
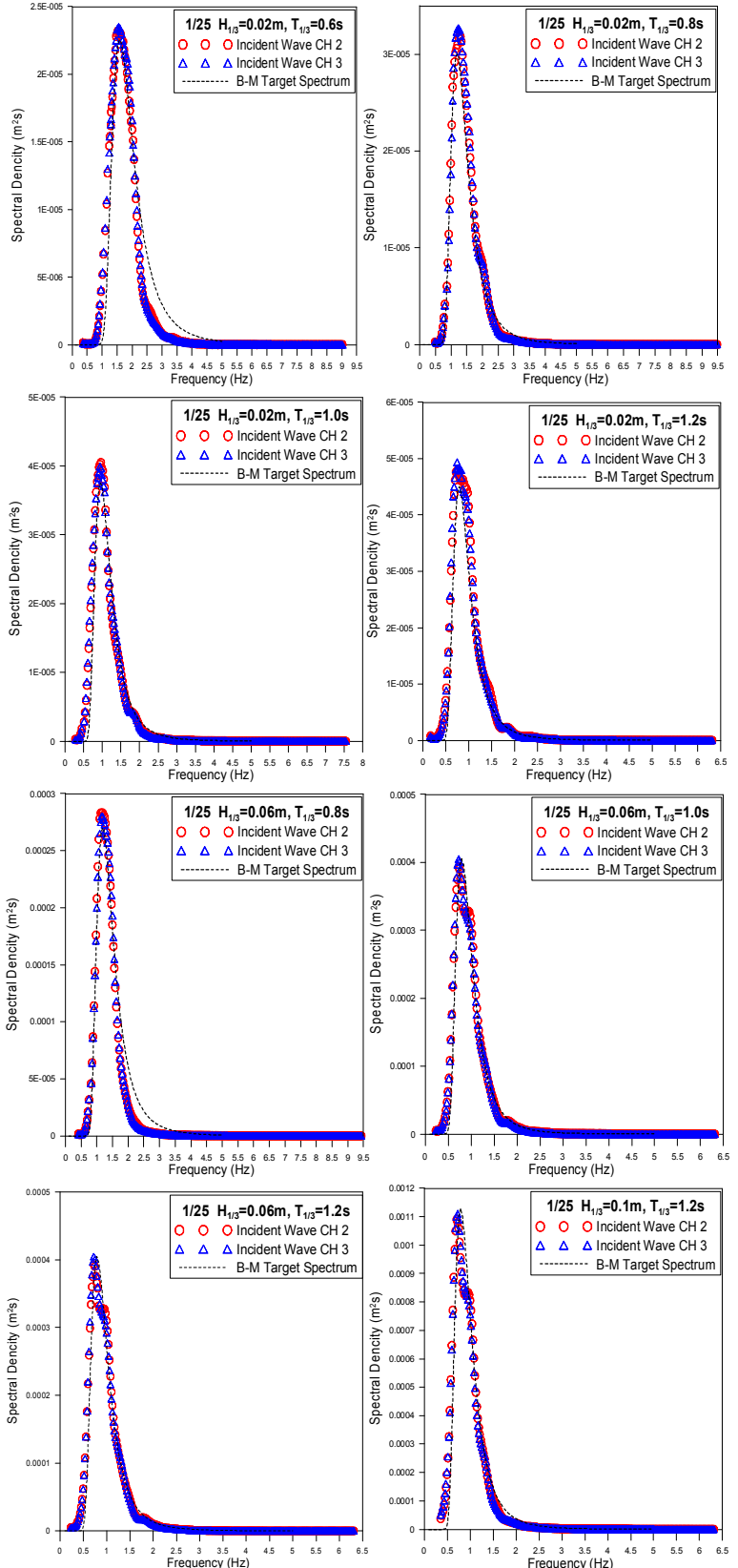

Fig. 7 Comparison of incident waves with the target $\mathrm{B}-\mathrm{M}$ spectrum

\subsection{Experimental list}

\section{1) Stability}

For the stability of foundation stones and cylindrical slit type unit blocks in the laboratory, incident waves up to 30 minutes of continuously were applied to the structure and observed whether the units and stones were displaced after each test. In addition, to analyze the status, the whole procedures were recorded by a digital camcorder.

\section{2) Reflection and Transmission}

The fraction of wave energy arrived at the slit cylinder 
will be scattered and dissipated. Part of them will reflected back to the front of structure face and others will be transmitted. Therefore, the decision of wave scattering effect from the design depends on the wave refection and transmission rates. As the incident wave that reaches to the structure is being reflected from structure, 3 wave gauges for reflection and 2 for transmission were set with a proper interval at a distance of one wave length away as shown in Fig. 5(b) and used FFT method to get the reflected and transmitted wave components from the wave records. By smoothing the records of the amplitudes for these waves, the reflection and transmission energy spectra could be predicted with Eq.(2).

$$
\begin{aligned}
& \mathrm{E}_{\mathrm{I}}=\int_{\mathrm{f}_{\text {min }}}^{f_{\text {max }}} S_{I}(f) d f \\
& \mathrm{E}_{\mathrm{R}}=\int_{\mathrm{f}_{\text {min }}}^{f_{\text {max }}} S_{R}(f) d f \\
& \mathrm{E}_{\mathrm{T}}=\iint_{\mathrm{f}_{\text {min }}}^{f_{\text {max }}} S_{T}(f) d f
\end{aligned}
$$

where, $E_{I}, E_{R}$ and $E_{T}$ are the energies of incident, reflected and transmitted waves, $S_{E}, S_{R}, S_{T}$ are the spectral density functions, respectively. Because the energies from Eq.(2) are proportional to the square of each wave height, the reflection and transmission rates might be represented as Eq.(3), respectively.

$$
\begin{aligned}
K_{R} & =\sqrt{\mathrm{E}_{\mathrm{R}} / \mathrm{E}_{\mathrm{I}}} \\
K_{T} & =\sqrt{\mathrm{E}_{\mathrm{T}} / \mathrm{E}_{\mathrm{I}}}
\end{aligned}
$$

\section{3) Wave force}

Measurement of the wave forces may be important for new type of shore structure, because there is no standard was made yet. In order to examine the wave forces on the cylindrical slit type breakwater, the typical column and plate of blocks may be tested by mounting the pressure sensors as shown in Fig. 6. Since the block is fixed at the bottom foundation in a flume, the structure requires mounting before filled with water. As will be discussed shortly, the test setup introduced difficulties in the measurement of the forces, particularly the maximum at the sea surface due to the shape of structure. The unit of measured forces is ton-force $/ \mathrm{m}^{2}$.

\section{Analysis and summary}

\subsection{Stability analysis of the breakwater}

After model calibration had been completed, the wave generator was run the cases as shown in Table 2 for 30 minutes at the high water level in spring tide. Measurements were performed to the armor concrete, cylindrical slit blocks and the back wall concrete of prototype and alternatives after each run. The results are shown in Table 3. It is found through the analysis of photos and digital camcorder shots that all cases were stable throughout the experiment. There were no significant difference between prototype and alternatives.

Table 3 Result of stability analysis for the breakwater designs

\begin{tabular}{|c|c|c|c|c|c|c|c|c|c|}
\hline \multicolumn{2}{|c|}{ Stability } & \multicolumn{2}{|c|}{ Prototype } & \multicolumn{3}{|c|}{ Alternative type 1} & \multicolumn{3}{c|}{ Alternative type 2} \\
\hline$H_{1 / 3}$ & $T_{1 / 3}$ & $\begin{array}{c}\text { Armor } \\
\text { concrete }\end{array}$ & $\begin{array}{c}\text { Cylindrical } \\
\text { slit blocks }\end{array}$ & $\begin{array}{c}\text { Armor } \\
\text { concrete }\end{array}$ & $\begin{array}{c}\text { Cylindrical } \\
\text { Slit blocks }\end{array}$ & $\begin{array}{c}\text { Leeside } \\
\text { wall } \\
\text { concrete }\end{array}$ & $\begin{array}{c}\text { Armor } \\
\text { concrete }\end{array}$ & $\begin{array}{c}\text { Cylindrical } \\
\text { slit blocks }\end{array}$ & $\begin{array}{c}\text { Leeside } \\
\text { wall } \\
\text { concrete }\end{array}$ \\
\hline $\begin{array}{c}0.5 \\
\mathrm{~m}\end{array}$ & $3 \mathrm{~s}$ & Stable & Stable & Stable & Stable & Stable & Stable & Stable & Stable \\
\cline { 2 - 11 } & $4 \mathrm{~s}$ & Stable & Stable & Stable & Stable & Stable & Stable & Stable & Stable \\
\hline $\begin{array}{c}1.5 \\
\mathrm{~m}\end{array}$ & $3 \mathrm{~s}$ & $*$ & $*$ & $*$ & $*$ & $*$ & $*$ & $*$ & $*$ \\
\cline { 2 - 11 } & $4 \mathrm{~s}$ & Stable & Stable & Stable & Stable & Stable & Stable & Stable & Stable \\
\hline \multirow{2}{*}{$\begin{array}{c}2.5 \\
\mathrm{~m}\end{array}$} & $3 \mathrm{~s}$ & $*$ & $*$ & $*$ & $*$ & $*$ & $*$ & $*$ & $*$ \\
\cline { 2 - 10 } & $4 \mathrm{~s}$ & $*$ & $*$ & $*$ & $*$ & $*$ & $*$ & $*$ & $*$ \\
\hline
\end{tabular}

\subsection{Reflection rates}

Reflection rates are calculated by square root of energy ratio of the reflected waves measured at the 3 gauges (channels 1, 2, 3) in front of the structure, with respect to the incident wave after separation of both waves. The prototype and alternative reflection rates are summarized in Table 4 and Fig. 9, together with transmission rates. The reflection rates are decreased as the wave period is getting longer, within the given short wave periods. Generally, the reflection rates show $0.4 \sim 0.5$ and those of the alternatives were known that slightly higher than the prototype due to the existence of leeside wall concrete.

\subsection{Transmission rates}

Transmission rates are calculated by square root of energy ratio of the transmitted waves measured at the 2 gauges (channels 4,5 ) behind the structure, with respect to the incident wave after separation. The prototype and alternative transmission rates are summarized in Table 4 and Fig. 10, together with reflection rates. The transmission rates are increased as the wave period is getting longer. The cases for leeside wall concrete together with horizontal plate give calm inner harbor water than the prototype.

Alternatives increased than prototype compared with the reflection rates as following, but there is no significant difference between alternatives and prototype. However, 
comparing with the transmission rates, alternatives decreased greatly than the prototype. From this we might judge that the alternatives help for calmness of harbor than the prototype.

Table 4 Comparison of reflection and transmission rates of prototype and alternatives

\begin{tabular}{|c|c|c|c|c|}
\hline \multicolumn{2}{|c|}{$\begin{array}{c}\text { Design } \\
\text { Wave }\end{array}$} & \multirow{2}{*}{$\begin{array}{l}\text { Prototype Reflection } \\
\text { /Transmission Rates }\end{array}$} & \multirow{2}{*}{$\begin{array}{l}\text { Alternative } \\
\text { type1 }\end{array}$} & \multirow{2}{*}{$\begin{array}{l}\text { Alternative } \\
\text { type2 }\end{array}$} \\
\hline$H_{1 / 3}$ & $T_{1 / 3}$ & & & \\
\hline \multirow{4}{*}{$0.5 \mathrm{~m}$} & $3 \mathrm{~s}$ & $0.38 / 0.41$ & $0.47 / 0.26$ & $0.56 / 0.20$ \\
\hline & $4 \mathrm{~s}$ & $0.36 / 0.42$ & $0.41 / 0.29$ & $0.48 / 0.22$ \\
\hline & $5 s$ & $0.33 / 0.47$ & $0.36 / 0.41$ & $0.46 / 0.32$ \\
\hline & $6 s$ & $0.32 / 0.47$ & $0.32 / 0.43$ & $0.40 / 0.35$ \\
\hline \multirow{4}{*}{$1.5 \mathrm{~m}$} & $3 \mathrm{~s}$ & $*$ & $*$ & $*$ \\
\hline & $4 \mathrm{~s}$ & $0.46 / 0.30$ & $0.50 / 0.23$ & $0.65 / 0.18$ \\
\hline & $5 s$ & $0.51 / 0.34$ & $0.54 / 0.26$ & $0.64 / 0.19$ \\
\hline & $6 s$ & $0.48 / 0.36$ & $0.47 / 0.34$ & $0.62 / 0.25$ \\
\hline \multirow{4}{*}{$2.5 \mathrm{~m}$} & $3 \mathrm{~s}$ & $*$ & $*$ & $*$ \\
\hline & $4 \mathrm{~s}$ & $*$ & $*$ & $*$ \\
\hline & $5 s$ & $*$ & $*$ & $*$ \\
\hline & $6 s$ & $0.41 / 0.36$ & $0.47 / 0.30$ & $0.60 / 0.22$ \\
\hline
\end{tabular}

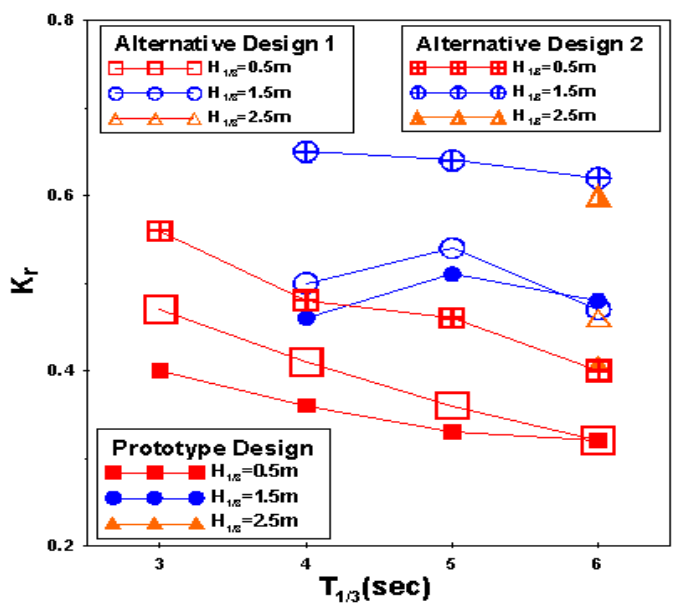

Fig. 8 Comparison of reflection rates

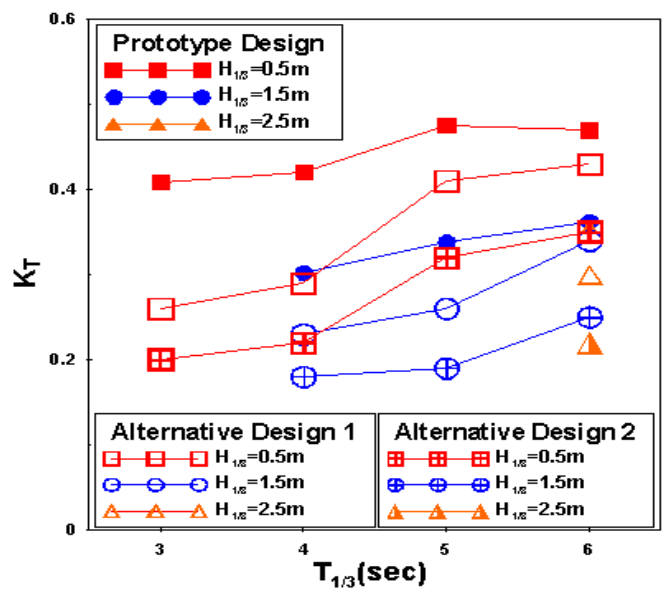

Fig. 9 Comparison of transmission rates

\section{Conclusions and field construction}

In this study a design of cylindrical slit type blocks and section forms have been made for the shore structure cross-sections of the breakwater. Revised section plans were tested in a wave tank of KMU. Three test series with twelve wave conditions were performed. The main conclusions and recommendations are as following.

1)Alternatives are better than the prototype in terms of transmission and tranquility.

2)Weak transmission through the cylindrical slit of structures is shown.

3)Also, stability analysis indicates that no units are moved and tilted for the adopted design waves in general.

The optimum design and construction method through this study were deduced and they were applied to the field construction at Seolly beach, which is a small beach of Namhae in the southeast coast of Korea, as shown in Fig. 11 and 12. Fig.13 shows the present status of construction in this field. Field measurement might be appeared after this construction work.

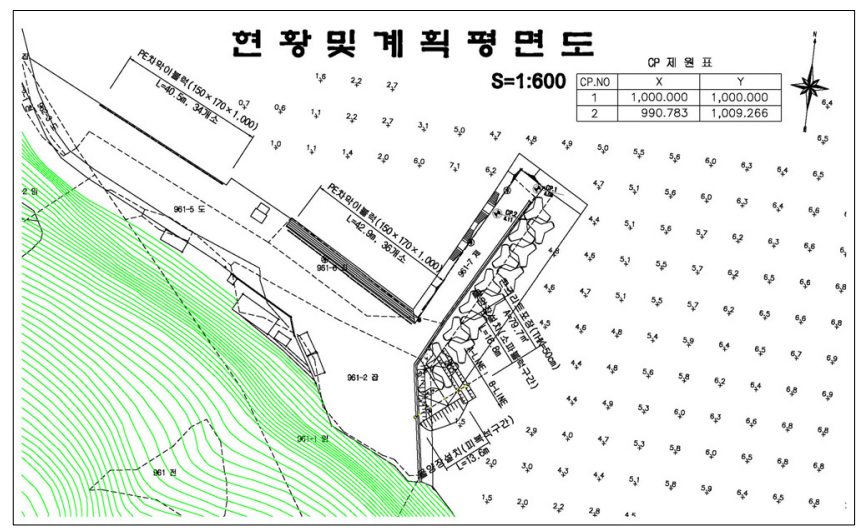

Fig. 10 Location and plan form of the field construction

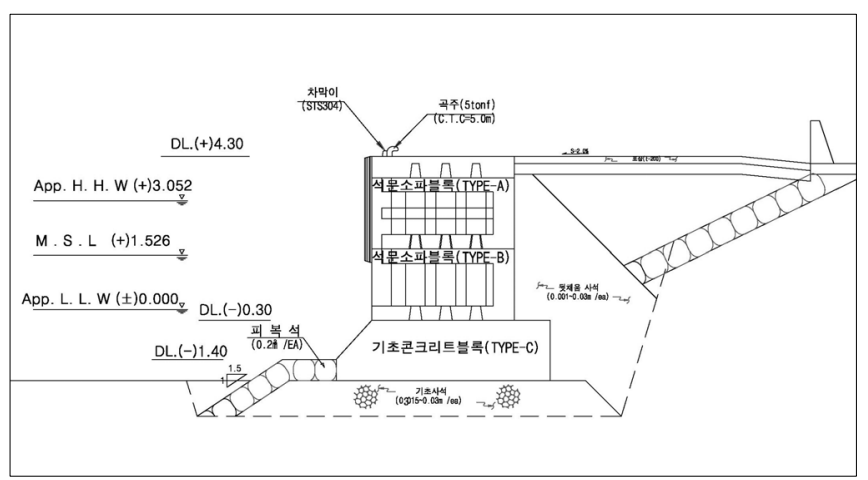

Fig. 11 Section plan of the field construction 


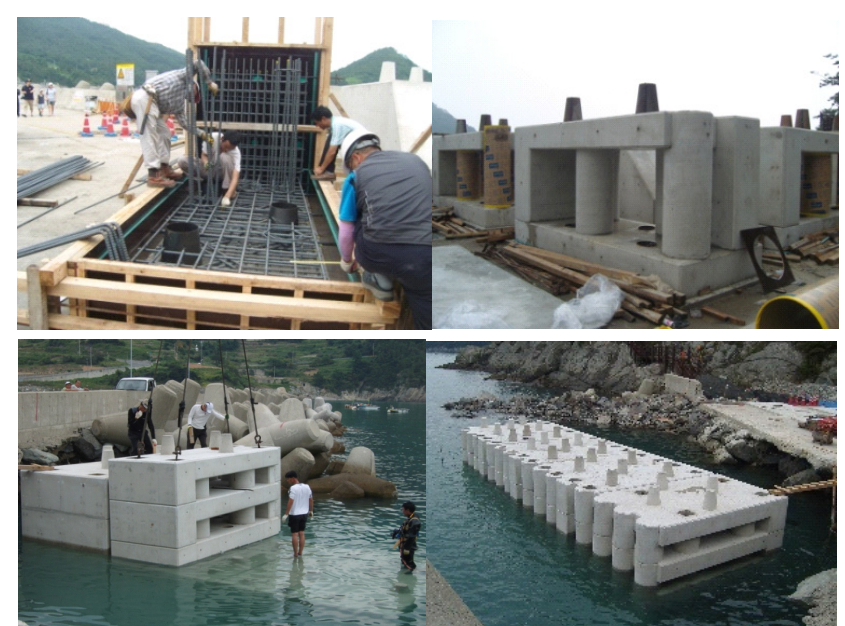

Fig. 12 Field construction and installation of units and structures

\section{References}

[1] Daewoo Construction (2004), Ulsan New Port Hydraulic Model Experiment.

[2] Han, J.M., Lee, J.S., Oh, Y.M., Kim, C.H., and Kim, G.J.(2006), Development of Environmental Unit Block.

[3] KORDI(2005), Hydraulic Model Experiment Report for Unit Block Design, Korea Ocean Research and Development Institute Report.

[4] Korea Institute of Construction Technology (2008), Hydraulic Model Experiment for Counter Facilities Design of Pohang Yeongil New Port.

[5] Sekwang Engineering Consultants (2004), Hydraulic Model Experiment for Dae-Cheon Port Dredging Work and North Breakwater Design.

[6] West Sea Fisheries Supervision Office (2008), Kugdong Harbor Multi-function Construction.

[7] Yoshimi Goda (1996), Random seas and design of maritime structures

Received 25 November 2009

Revised 31 December 2009

Accepted 31 December 2009 